\title{
Evaluation of a two-generation rat model for vitamin A deficiency and the interrelationship with iron metabolism
}

\author{
BY ANNET J. C. ROODENBURG ${ }^{1,2}$, CLIVE E. WEST ${ }^{1,3 *}$, ROBERT HOVENIER ${ }^{1}$ \\ AND ANTON C. BEYNEN ${ }^{2}$ \\ ${ }^{1}$ Department of Human Nutrition, Wageningen Agricultural University, Bomenweg 2, \\ 6703 HD Wageningen, The Netherlands \\ ${ }^{2}$ Department of Laboratory Animal Science, Utrecht University, Yalelaan 2, 3584 CM Utrecht, \\ The Netherlands \\ ${ }^{3}$ Center for International Health, Rollins School of Public Health, Emory University, \\ 1518 Clifton Road N.E., Atlanta, GA 30322, USA
}

(Received 2 June 1994 - Revised 18 January 1995-Accepted 16 February 1995)

\begin{abstract}
In order to induce a range of vitamin A-deficient states in young growing rats and to study the effect of vitamin A deficiency on Fe status, we designed the following two-generation experiment. Dams were fed on diets with one of five vitamin $A$ levels from 2 weeks before and throughout pregnancy and lactation. The pups received the same diets as their mothers both before and after weaning. The five dietary levels of vitamin $A$ were $1200,450,150,75$ and 0 retinol equivalents/kg feed. Vitamin $A$ intake did not affect reproduction outcome, nor were body and liver weights of the pups affected when they were 3.5 weeks old. Male pups with normal vitamin $A$ status had higher plasma retinol levels than female pups. Vitamin A status of the offspring was affected from 3.5 weeks onwards. Body and liver weights were decreased in the male pups given the lowest dietary vitamin A levels from week 6.5 onwards but not in the female pups. Fe status was marginally affected. Haemoglobin levels were increased and total Fe-binding capacity was decreased in the groups given no dietary vitamin $A$ at week $9 \cdot 5$. Splenic Fe was increased only in the male pups given the lowest levels of dietary vitamin A. However, as a whole, Fe status was only mildly affected and subject to considerable variation. We conclude that the two-generation rat model described here is not suitable for studying effects of vitamin A deficiency on Fe metabolism.
\end{abstract}

Vitamin A: Iron: Rat model

Vitamin A deficiency is a major public health concern and affects not only child morbidity and mortality (Beaton et al. 1993), but is also associated with impaired Fe status (Mejía \& Arroyave, 1982; Bloem et al. 1989; Suharno et al. 1992). Intervention trials, in areas where vitamin A deficiency is endemic, have shown that vitamin A supplementation produces increased blood haemoglobin levels (Mohanram et al. 1977; Mejía \& Chew, 1988; Muhilal et al. 1988; Bloem et al. 1990; Suharno et al. 1993). However, the mechanisms by which vitamin $\mathrm{A}$ influences $\mathrm{Fe}$ metabolism are still unclear. To develop an animal model for studying these mechanisms we have induced acute vitamin A deficiency in young growing male rats by feeding them no vitamin A from the age of 6 weeks onwards (Roodenburg $e t$ al. 1994). Vitamin A deficiency in the rats develops quickly, and consequently does not mirror the situation in humans with impaired vitamin A status. Therefore, we have attempted to design a rat model that would resemble the situation in children with chronic

\footnotetext{
* For reprints.
} 
vitamin A deficiency. For this purpose we used a two-generation model with dams and their pups fed on vitamin A-deficient diets. On the basis of studies in chickens by West $e t$ al. (1992) it was anticipated that the two-generation rat model would produce young rats with different, but more-or-less constant, vitamin A status. In the male and female offspring we assessed vitamin A status by determination of plasma and liver retinol concentrations. Fe status was assessed by measuring haemoglobin, plasma Fe, total Fe-binding capacity and Fe in liver, spleen and bone.

\section{MATERIALS AND METHODS}

The experiment was approved and supervised by the animal welfare officer of Wageningen Agricultural University.

\section{Animals, diets and housing}

Fifty-two female and twenty-eight male Wistar rats ( $\mathrm{Cpb}: \mathrm{WU})$, aged 10 weeks, were used for breeding. Before they entered the study the rats had been fed on a commercial pelleted diet (RMH-B; Hope Farms, Woerden, The Netherlands). According to the manufacturer, minimum levels of vitamin $\mathrm{A}$ and $\mathrm{Fe}$ in the natural-ingredient diet were 5940 retinol equivalents (RE) $/ \mathrm{kg}$ and $165 \mathrm{mg} / \mathrm{kg}$ respectively.

During the experiment the rats were housed in groups of four or five animals of the same sex in stainless steel cages with wire mesh bases $(300 \times 420 \times 190 \mathrm{~mm})$. All animals received a control diet (Table 1) containing sufficient vitamin A (1200 RE/ $\mathrm{kg}$ feed), for a period of 4 weeks. This diet was formulated according to the nutrient requirements of rats (National Research Council, 1978). Then, 2 weeks before mating, the female rats were divided into five groups matched for body weight, and transferred to wire-topped, polycarbonate cages $(345 \times 225 \times 160 \mathrm{~mm})$ with a layer of sawdust as bedding. They were housed two or one per cage. The five groups of ten or eleven animals received diets with different levels of added vitamin $\mathrm{A}(1200,450,150,75$ or $0 \mathrm{RE} / \mathrm{kg}$ feed) until they were killed after weaning of the pups. The analysed $\mathrm{Fe}$ content of the diets was $60 \mathrm{mg} \mathrm{Fe} / \mathrm{kg}$ feed. The purified diets (Table 1) were pelleted (diameter $10 \mathrm{~mm}$ ). Male rats continued to receive the control diet.

For mating, one male rat was housed together with one or two females, aged 16 weeks, for a period of $10 \mathrm{~d}$. After this period the female rats were housed individually in the polycarbonate cages until the pups were weaned. All female rats appeared to be healthy. The proportion of dams delivering, litter size and the proportion of live births were similar for the five groups (Table 2). Nest size was standardized to 10-12 pups. Due to this procedure, three dams that delivered small nests did not lactate and were excluded from the analysis. All mother rats were killed on the same day, 1-7 d after the end of the lactation and nursing period $(21 \mathrm{~d})$. Blood and organs were collected. Results from the rats that did not deliver $(n 13)$ or delivered but did not lactate $(n 3)$ were left out of the analysis.

Of the total of 427 pups, 342 were born $24-26 \mathrm{~d}$ after the start of the temporary cohabitation of the males and females; 150 out of the 342 were used in the present experiment. The other pups were used in two other experiments (Roodenburg et al. 1996; A. J. C. Roodenburg, C. E. West and A. C. Beynen, unpublished results). When the pups were 3.5 weeks (25-27 d) old, five male and five female pups from each group were selected at random and killed. Blood and organs were collected. From the other animals, ten male and ten female pups from each group were housed in groups of five animals of the same sex in stainless steel cages with wire mesh bases $(300 \times 420 \times 190 \mathrm{~mm})$ and continued to receive the same diet as their respective mothers. At both age 6.5 and 9.5 weeks ( $46-48$ and 67-69 d), one cage containing five male and five female pups from each group was removed from the study. The rats were then killed and blood and organs were collected. 
Table 1. Composition of the pelleted diets $(\mathrm{g} / \mathrm{kg})$

\begin{tabular}{|c|c|}
\hline Ingredients & \\
\hline $\begin{array}{l}\text { Casein } \\
\text { Maize oil } \\
\text { Coconut fat } \\
\text { Glucose } \\
\text { Maize starch } \\
\text { Cellulose } \\
\mathrm{CaCO}_{3} \\
\mathrm{NaH}_{2} \mathrm{PO}_{4} \cdot 2 \mathrm{H}_{2} \mathrm{O} \\
\mathrm{MgCO}_{3} \\
\mathrm{KCl} \\
\mathrm{KHCO}_{3} \\
\mathrm{FeSO}_{4} \cdot 7 \mathrm{H}_{2} \mathrm{O} \text { (mg) } \\
\text { Molasses } \\
\text { Vitamin A preparation (retinol equivalents (RE))* } \\
\text { Mineral premix (iron-free) } \dagger \\
\text { Vitamin premix (vitamin A-free) }\end{array}$ & $\begin{array}{l}151 \\
25 \\
25 \\
329 \cdot 6 \\
329 \cdot 6 \\
30 \\
12 \cdot 4 \\
15 \cdot 1 \\
1 \cdot 4 \\
1 \cdot 0 \\
7 \cdot 7 \\
124 \\
50 \\
1200 / 450 / 150 / 75 / 0 \\
10 \\
12\end{array}$ \\
\hline
\end{tabular}

* Rovimix A 500 150 RE/mg (F. Hoffman-La Roche \& Co. Ltd, Basle, Switzerland), consisting of retinyl acetate and retinyl palmitate; of this preparation $1200,450,150,75$ or $0 \mathrm{RE} / \mathrm{kg}$ feed was added.

$\dagger$ The mineral premix consisted of (mg): $\mathrm{MnO}_{2} 79, \mathrm{ZnSO}_{4} \cdot \mathrm{H}_{2} \mathrm{O} 33, \mathrm{NiSO}_{4} \cdot 6 \mathrm{H}_{2} \mathrm{O} 13, \mathrm{NaF} 2, \mathrm{KI} 0 \cdot 2$, $\mathrm{CuSO}_{4} .5 \mathrm{H}_{2} \mathrm{O} 15 \cdot 7, \mathrm{Na}_{2} \mathrm{SeO}_{3} .5 \mathrm{H}_{2} \mathrm{O} 0.3, \mathrm{CrCl}_{3} .6 \mathrm{H}_{2} \mathrm{O} 1.5, \mathrm{SnCl}_{2} .2 \mathrm{H}_{2} \mathrm{O} 1 \cdot 9, \mathrm{NH}_{4} \mathrm{VO}_{3} 0 \cdot 2$, maize meal $9853 \cdot 2$.

† The vitamin premix consisted of $(\mathrm{mg})$ : thiamin 4 , riboflavin 3, niacin 20 , D,L-calcium pantothenate $17 \cdot 8$, pyridoxine 6 , cyanocobalamin 50 , choline chloride 2000 , pteroylglutamic acid 1 , biotin 2 , menadione 0.05 , $\mathrm{D}, \mathrm{L}-\alpha$ tocopheryl acetate 60 , cholecalciferol 2 , maize meal $9834 \cdot 15$.

Table 2. Reproductive outcome and litter size of dams fed with different amounts of vitamin $A$

\begin{tabular}{cccc}
\hline $\begin{array}{c}\text { Dietary } \\
\text { retinol } \\
\text { (RE/kg feed) }\end{array}$ & $\begin{array}{c}\text { Dams } \\
\text { delivering } \\
\text { (number/total) }\end{array}$ & $\begin{array}{c}\text { Litter } \\
\text { size } \\
n \text { (range) }\end{array}$ & $\begin{array}{c}\text { Live } \\
\text { births } \\
(\%)\end{array}$ \\
\hline 1200 & $7 / 10(70)$ & $9 \cdot 8(2-12)$ & 97 \\
450 & $7 / 10(70)$ & $11 \cdot 6(9-14)$ & 96 \\
150 & $9 / 10(90)$ & $11 \cdot 3(2-14)$ & 97 \\
75 & $7 / 11(64)$ & $10 \cdot 7(9-14)$ & 97 \\
0 & $9 / 11(82)$ & $11 \cdot 1(7-14)$ & 97 \\
\hline
\end{tabular}

RE, retinol equivalents.

All animals had free access to feed and demineralized water throughout. During the experiment, body weight and feed intake per cage were recorded at weekly intervals. Feed intake was corrected for spillage losses. A controlled light-dark cycle (light on: 06.00-18.00 hours), temperature $\left(20-22^{\circ}\right)$ and relative humidity $(50-60 \%)$ were maintained in the animal room.

\section{Collection of samples}

Blood was collected in heparinized vials by orbital puncture while the rats were under diethyl ether anaesthesia. The blood was stored at $0^{\circ}$ for haematological examination on the same day. Then, plasma was isolated by centrifugation $(10 \mathrm{~min}, 3000 \mathrm{rev} . / \mathrm{min})$ and stored at $-20^{\circ}$ until analysis, except for $250 \mu \mathrm{l}$ which was stored at $-80^{\circ}$ for subsequent 
analysis of retinol. Immediately after bleeding, the anaesthetized rats were decapitated. Liver, spleen and both hindlegs were removed and stored at $-20^{\circ}$ until analysis. Organs were weighed before storage.

\section{Chemical analyses}

Haemoglobin concentration was analysed with a blood cell counter (Model K-1000; Sysmex, IJsselstein, The Netherlands). Plasma Fe concentrations and total Fe-binding capacity were determined spectrophotometrically using a commercial test kit (Roche Nederland, Mijdrecht, The Netherlands). Spleen and liver were washed with saline $(9 \mathrm{~g} \mathrm{NaCl} / \mathrm{l})$ and liver was homogenized as described below. Liver homogenate, spleen and tibia were dried $\left(100^{\circ}, 12 \mathrm{~h}\right)$ and ashed $\left(500^{\circ}, 16 \mathrm{~h}\right)$. The ash was dissolved in $1 \mathrm{ml} 6 \mathrm{M}-\mathrm{HCl}$ and diluted with demineralized water. Fe was measured by flame atomic absorption spectrometry (Model AA-475, Varian, Springvale, Australia). Fe in tibia was calculated as the mean of left and right tibias.

Plasma and liver retinol concentrations were measured by reversed phase HPLC. Plasma $(100 \mu \mathrm{l})$ was mixed vigorously with ethanol $(900 \mathrm{ml} / \mathrm{l} ; 400 \mu \mathrm{l})$, and after centrifuging (10 min, $3000 \mathrm{rev} . / \mathrm{min})$, retinol was determined directly in the supernatant fraction and calibrated against solutions of retinol in ethanol $(720 \mathrm{ml} / 1)$. Serum pools with retinol concentrations of 0.63 or $2.16 \mu \mathrm{mol} / 1$ were used as external controls. The combined between- and within-run variations of retinol determination in the two pools were 6 and $4 \%(\mathrm{CV})$. The particulars of the HPLC system used were as follows: injection volume, $50 \mu \mathrm{l}$; pre-column, $10 \times 3 \mathrm{~mm}$ stainless steel packed with Chromguard reversed phase (Chrompack, Middelburg, The Netherlands); column, $100 \times 3 \mathrm{~mm}$ glass cartridge packed with Spherisorb-ODS ( $5 \mu \mathrm{m}$; Chrompack); isocratic pump (Spectra Physics, San José, CA, USA); UV/visible detector (Spectra Focus, forward optical scanning detector; Spectra Physics) with wavelength of $325 \mathrm{~nm}$; mobile phase, methanol-water $(90: 10, \mathrm{v} / \mathrm{v})$; flow rate, $0.4 \mathrm{ml} / \mathrm{min}$; run time, $5 \mathrm{~min}$; retention time, $3.5 \mathrm{~min}$.

Liver total retinol was determined after saponification and extraction. Liver homogenate ( $200 \mu \mathrm{l}$; liver-demineralized water, $1: 5$, w/v) was digested by heating at $100^{\circ}$ for $15 \mathrm{~min}$ in $1.5 \mathrm{ml} 0.7 \mathrm{M}-\mathrm{KOH}$ in ethanol $(500 \mathrm{ml} / 1$ containing $6 \mathrm{~g} / 1$ pyrogallol) and, after cooling, the mixture was extracted twice with $4 \mathrm{ml}$ hexane. Standards with retinol acetate in absolute ethanol were processed identically and used for calibration. After centrifugation (3000 rev./min, $6 \mathrm{~min}$ ) the upper layer of the hexane extract was collected and retinol determined using the HPLC method described above, except for the following conditions: injection volume, $20 \mu \mathrm{l}$; mobile phase, methanol-water $(95: 5, \mathrm{v} / \mathrm{v})$; flow rate, $0.4 \mathrm{ml} / \mathrm{min}$; run time, $3 \mathrm{~min}$; retention time, $1.6 \mathrm{~min}$. Recovery, determined by adding known amounts of retinol acetate to homogenates before digestion, was $90-95 \%$. A pooled liver homogenate with target value of $98 \mu \mathrm{mol}$ retinol/1 was used as an external control. The combined between- and within-run variation of retinol determination was $6 \%(\mathrm{CV})$. No impurities were detected when peak purity was tested using the scanning function of the detector over a wavelength range of $220-600 \mathrm{~nm}$.

\section{Statistical analysis}

The data from the offspring were subjected to two-way ANOVA with vitamin A feeding and sex as independent variables. The data from the dams and from the male and female pups separately at the three experimental points were subjected to one-way ANOVA with vitamin A feeding as independent variable. Contrasts based on Student's $t$ test were used to test whether the groups given $0-450 \mathrm{RE} / \mathrm{kg}$ feed were significantly different from the control group given $1200 \mathrm{RE} / \mathrm{kg}$ feed. Bonferroni's adaptation for multiple comparisons was used. 
Table 3. Retinol in plasma and liver, body weight and liver weight of dams fed with different amounts of vitamin $A$ at 22-29 d after parturition $\dagger$

\begin{tabular}{|c|c|c|c|c|c|}
\hline $\begin{array}{c}\text { Dietary } \\
\text { retinol } \\
\text { (RE/kg feed) }\end{array}$ & $n$ & $\begin{array}{c}\text { Plasma } \\
\text { retinol } \\
(\mu \mathrm{mol} / \mathrm{l})\end{array}$ & $\begin{array}{c}\text { Liver retinol } \\
\text { ( } \mu \mathrm{mol} / \mathrm{g} \text { wet } \\
\text { weight) }\end{array}$ & $\begin{array}{c}\text { Body wt } \\
\text { (g) }\end{array}$ & $\begin{array}{l}\text { Liver wt } \\
\text { (g) }\end{array}$ \\
\hline 1200 & 6 & 0.82 & 0.73 & $260 \cdot 9$ & $10 \cdot 9$ \\
\hline 450 & 7 & 1.02 & $0.33^{*}$ & $272 \cdot 9$ & 12.8 \\
\hline 150 & 8 & 0.94 & $0.28 *$ & $261 \cdot 5$ & 10.4 \\
\hline 75 & 6 & 1.04 & $0.29^{*}$ & 258.0 & $11 \cdot 1$ \\
\hline 0 & 9 & 1.01 & $0.22^{*}$ & $253 \cdot 3$ & 10.1 \\
\hline Pooled SE & & 0.31 & 0.03 & 44.7 & 4.8 \\
\hline
\end{tabular}

RE, retinol equivalents.

${ }^{*}$ Mean values were significantly different from that of the control group fed on a diet containing $1200 \mathrm{RE} / \mathrm{kg}$, $P<0.0125$ (Student's $t$ test).

$\dagger$ For details of diets and procedures, see Table 1 and pp. 690-692.

$\ddagger$ Pooled SE were calculated as SE $=\sqrt{ } \mathrm{MS}_{\text {within }} / \sqrt{ } n$, with $n 6$, the smallest group and $\mathrm{MS}_{\mathrm{within}}$, as mean squares derived from one-way ANOVA.

\section{RESULTS}

\section{Characteristics of dams}

The dams did not differ in body weight, liver weight and plasma retinol levels (Table 3). Only liver retinol concentration was decreased in the groups fed on the restricted levels of vitamin A when compared with the control group (Table 3). Fe status, as illustrated by $\mathrm{Fe}$ levels in organs, blood haemoglobin, plasma Fe and total Fe-binding capacity, did not differ among the five groups of dams (Table 4).

\section{Vitamin A status of pups}

Plasma retinol was reduced in the groups given 0,75 and $150 \mathrm{RE} / \mathrm{kg}$ feed in both male and female pups when compared with their control group given $1200 \mathrm{RE} / \mathrm{kg}$ feed. Levels of plasma retinol in the control groups were lower in female pups when compared with male pups (Fig. 1). This was shown by a significant sex effect $(P<0.001)$ in the variance analysis. Liver retinol was low in the groups given $450 \mathrm{RE} / \mathrm{kg}$ feed and undetectable in the groups given lower levels of vitamin A both in female and in male pups. The control groups seemed to accumulate hepatic retinol (Fig. 1). ANOVA revealed a small effect of $\operatorname{sex}(P=0.034)$ on liver retinol concentrations.

\section{Body weight and liver weight of pups}

Dietary vitamin A reduced body weight and liver weight of the young rats from week 6.5 onwards in the groups of male pups given the lowest levels of dietary vitamin A (0-150 RE $/ \mathrm{kg}$ ), compared with the control group, which received $1200 \mathrm{RE} / \mathrm{kg}$ feed (Fig. 2). This could be explained in part by reduced feed intakes, which were (at week 9.5) 20.2, $19 \cdot 2,19.0 \mathrm{~g} / \mathrm{d}$ in the groups given 1200,450 and $150 \mathrm{RE} / \mathrm{kg}$ respectively, $16.3 \mathrm{~g} / \mathrm{d}$ in the group given $75 \mathrm{RE} / \mathrm{kg}$ and $13.1 \mathrm{~g} / \mathrm{d}$ in the male pups given no vitamin $\mathrm{A}$. The female pups that received no dietary vitamin A had lower liver weights at week 9.5 when compared with the control group (Fig. 2). Body weight and liver weight were lower in the female than in the male pups $(P<0.001$, ANOVA). Feed intake, also, was lower in female pups, $12.9 \mathrm{~g} / \mathrm{d}$ (overall mean) when compared with male pups, $17 \cdot 6 \mathrm{~g} / \mathrm{d}$, at week $9 \cdot 5$. 
Table 4. Iron status of dams fed with different amounts of vitamin $A^{*}$

\begin{tabular}{|c|c|c|c|c|c|c|c|}
\hline \multirow{2}{*}{$\begin{array}{c}\text { Dietary } \\
\text { retinol } \\
\text { (RE/kg feed) }\end{array}$} & \multirow[b]{2}{*}{$n$} & \multicolumn{3}{|c|}{ Iron in organs ( $\mu \mathrm{mol} / \mathrm{g}$ dry $w \mathrm{t})$} & \multirow{2}{*}{$\begin{array}{l}\text { Haemoglobin } \\
\text { (mmol/l) }\end{array}$} & \multirow{2}{*}{$\begin{array}{c}\text { Total } \\
\text { iron-binding } \\
\text { capacity } \\
(\mu \mathrm{mol} / \mathrm{l})\end{array}$} & \multirow{2}{*}{$\begin{array}{c}\text { Plasma } \\
\text { iron } \\
(\mu \mathrm{mol} / 1)\end{array}$} \\
\hline & & Liver & Spleen & Tibia & & & \\
\hline 1200 & 6 & $8 \cdot 04$ & $43 \cdot 4$ & $1 \cdot 48$ & $10 \cdot 12$ & $86 \cdot 81$ & $62 \cdot 86$ \\
\hline 450 & 7 & $4 \cdot 88$ & $45 \cdot 5$ & 1.57 & $9 \cdot 80$ & $94 \cdot 31$ & $60 \cdot 31$ \\
\hline 150 & 8 & $7 \cdot 25$ & $62 \cdot 9$ & $1 \cdot 80$ & $9 \cdot 68$ & $85 \cdot 71$ & $62 \cdot 03$ \\
\hline 75 & 6 & $8 \cdot 25$ & $58 \cdot 3$ & $1 \cdot 76$ & $10 \cdot 05$ & $87 \cdot 14$ & $60 \cdot 05$ \\
\hline 0 & 9 & 8.85 & $72 \cdot 1$ & 1.94 & 9.99 & $82 \cdot 54$ & $62 \cdot 08$ \\
\hline Pooled SE† & & $7 \cdot 20$ & $49 \cdot 7$ & $0 \cdot 81$ & 1.03 & 18.52 & $21 \cdot 57$ \\
\hline
\end{tabular}

RE, retinol equivalents.

* For details of diets and procedures, see Table 1 and pp. 690-692.

$\dagger$ Pooled SE are calculated as SE $=\sqrt{ } \mathrm{MS}_{\text {within }} / \sqrt{ } n$, with $n 6$, the smallest group and $\mathrm{MS}_{\mathrm{within}}$, as mean squares derived from one-way ANOVA.
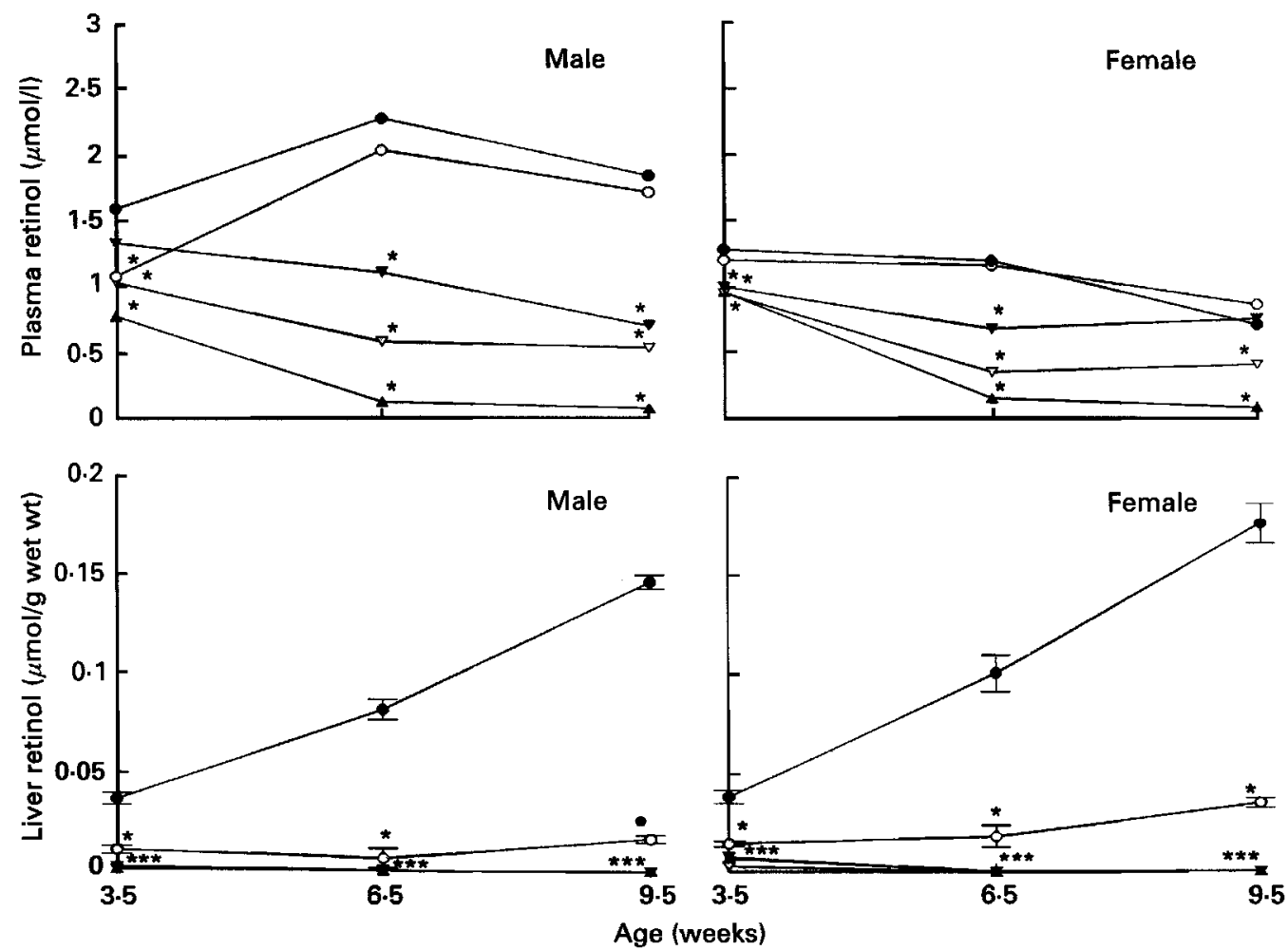

Fig. 1. Plasma retinol and liver retinol concentrations in male and female rat pups fed on diets containing the following amounts of vitamin A: (O), 1200 retinol equivalents (RE; control group); (O) $450 \mathrm{RE}$; ( $)$ ), $150 \mathrm{RE}$; $(\nabla), 75 \mathrm{RE}$ and (A) $0 \mathrm{RE} / \mathrm{kg}$ feed. Values are means for five animals/group; pooled sE for plasma retinol were: males, week 3.50 .43 , week 6.50 .58 , week 9.50 .52 ; females, week 3.50 .31 , week 6.50 .31 , week $9.50 .29 \mu \mathrm{mol} / 1$. Separate SE for liver retinol are represented by vertical bars for the groups given 1200 and $450 \mathrm{RE} / \mathrm{kg}$. * Mean values were significantly different from that of the control, $P<0 \cdot 0125$. ANOVA showed significant effects of sex $(P<0.001)$ and vitamin A feeding $(P<0.001)$ and their interaction $(P<0.001)$ for plasma retinol, and of sex $(P=0.031)$ and vitamin A feeding $(P<0.001)$ for liver retinol. 

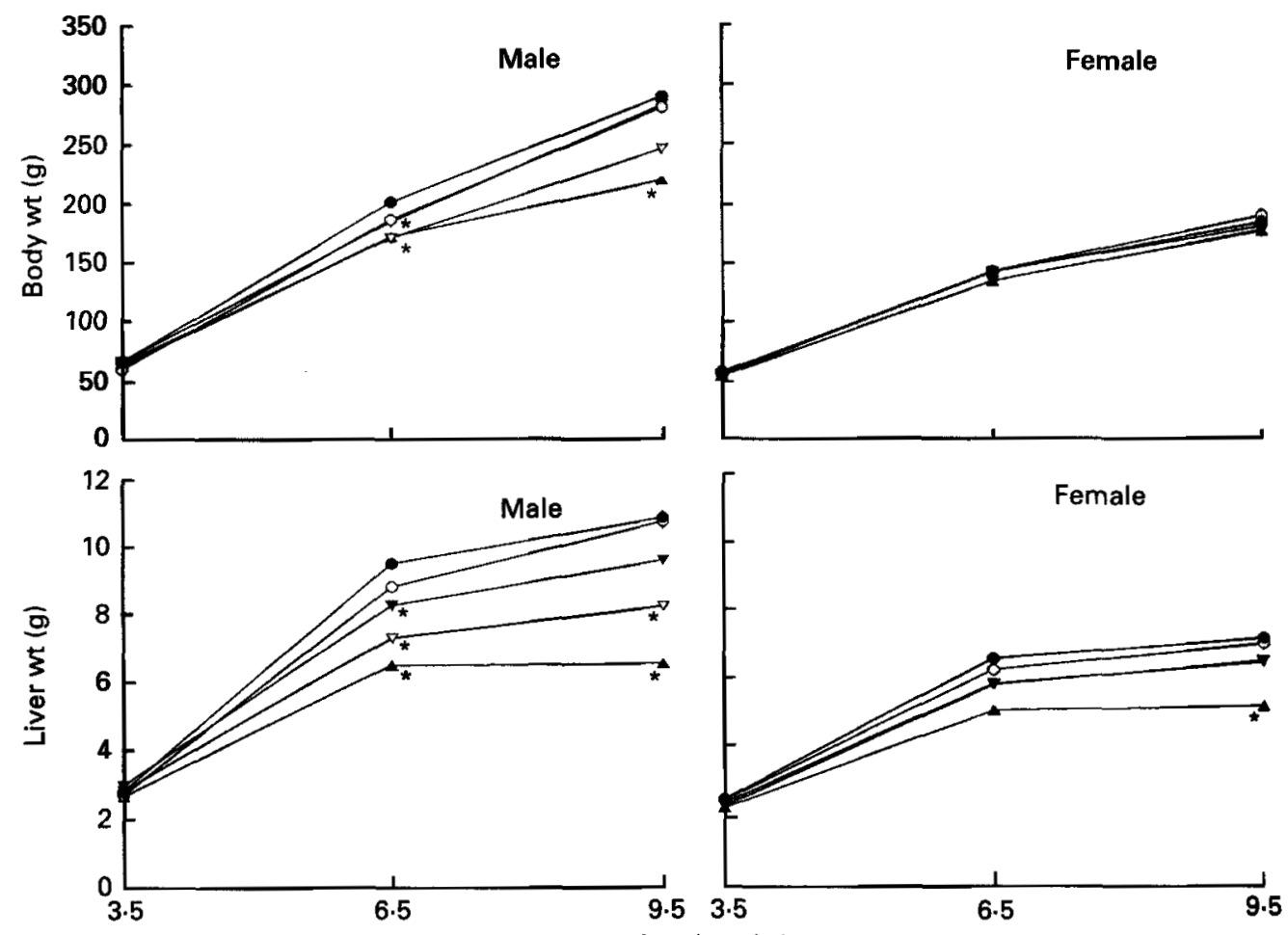

Age (weeks)

Fig. 2. Body weight and liver weight in male and female rat pups fed on diets containing the following amounts of vitamin A: (O), 1200 retinol equivalents (RE; control group); (O) $450 \mathrm{RE;} \mathrm{( \nabla ),} 150 \mathrm{RE} ;(\nabla), 75 \mathrm{RE}$ and (A) $0 \mathrm{RE} / \mathrm{kg}$ feed. Values are means of five animals/group; pooled SE for body weight were: males, week $3.512 \cdot 1$, week $6.526 \cdot 1$, week $9 \cdot 559.4$; females, week 3.512 .4 , week 6.532 .0 , week $9.538 .1 \mathrm{~g}$; and those for liver weight were: males, week 3.50 .64 , week 6.51 .33 , week 9.52 .52 ; females, week 3.51 .37 , week 6.51 .91 , week $9.51 .90 \mathrm{~g}$. * Mean values were significantly different from that of the control group, $P<0.0125$. ANOVA showed significant effects of sex $(P<0.001)$ for body weight and of sex $(P<0.001)$ and vitamin A feeding $(P=0.007)$ for liver weight.

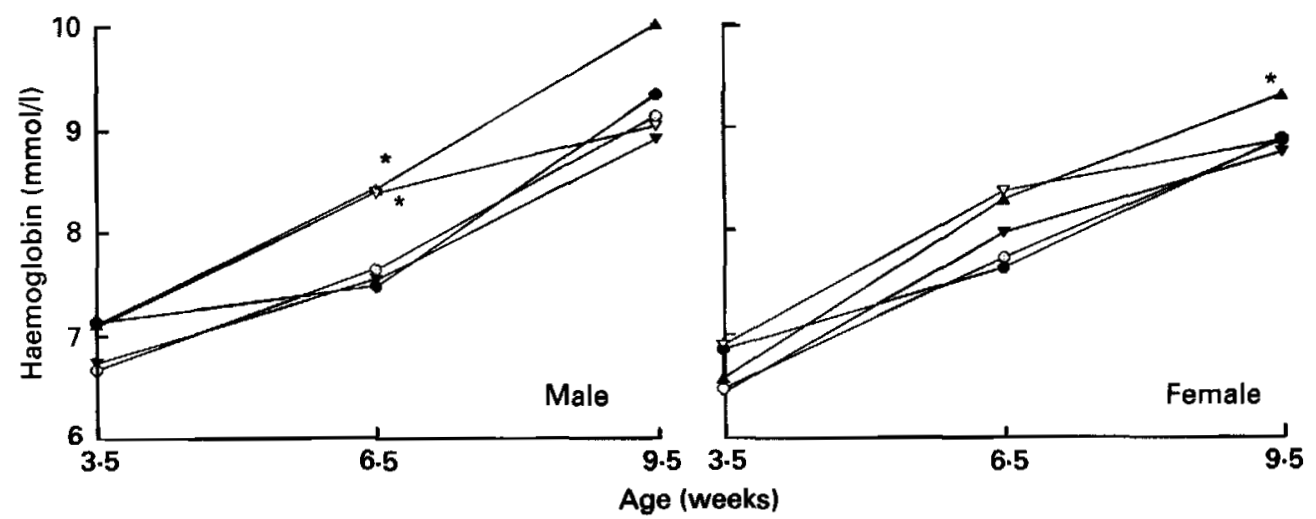

Fig. 3. Haemoglobin concentration in male and female rat pups fed on diets containing the following amounts of vitamin A: (O), 1200 retinol equivalents (RE; control group); (O) $450 \mathrm{RE} ;(\boldsymbol{\nabla}), 150 \mathrm{RE} ;(\nabla), 75 \mathrm{RE}$ and (A) $0 \mathrm{RE} / \mathrm{kg}$ feed. Values are means for five animals/group; pooled SE were: males, week $3.50 \cdot 71$, week 6.50 .63 , week 9.5 1.08; females, week 3.51 .04 , week 6.51 .07 , week $9.50 .44 \mathrm{mmol} / 1$. * Mean values were significantly different from that for the control group, $P<0.0125$. ANOVA showed significant effects of $\operatorname{sex}(P=0.021)$ and vitamin $\mathbf{A}$ feeding $(P=0.004)$. 

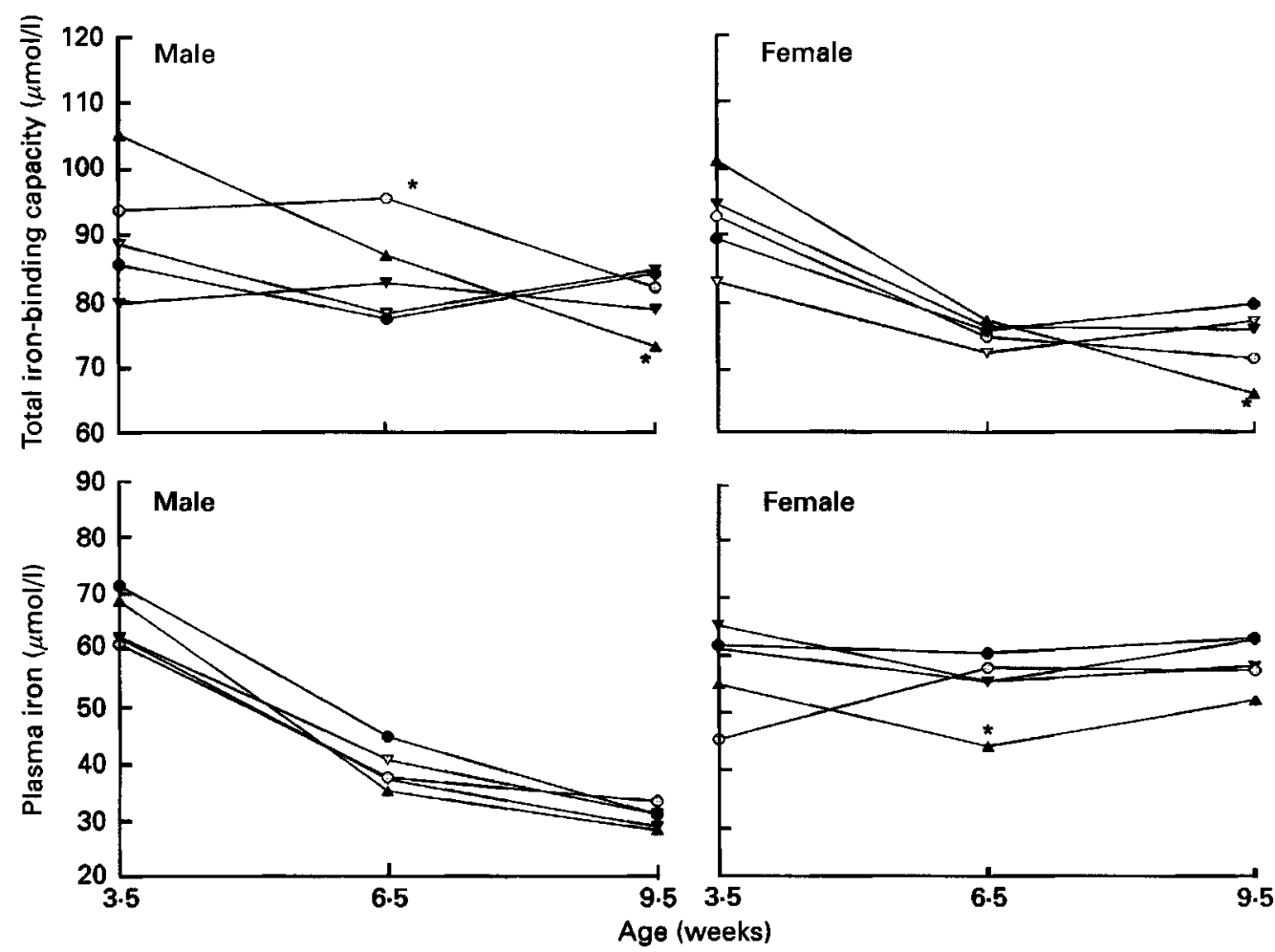

Fig. 4. Total iron-binding capacity and plasma iron concentrations in male and female rat pups fed on diets containing the following amounts of vitamin A: (O), 1200 retinol equivalents (RE; control group); (O) 450 RE; $(\nabla), 150 \mathrm{RE} ;(\nabla), 75 \mathrm{RE}$ and $(\Delta) 0 \mathrm{RE} / \mathrm{kg}$ feed. Values are means for five animals/group; pooled SE for total iron-binding capacity were: males, week 3.530 .6 , week 6.515 .6 , week $9.59 \cdot 3$; females, week 3.536 .9 , week $6.517 \cdot 1$, week $9.511 .8 \mu \mathrm{mol} / \mathrm{l}$, and for plasma iron were: males, week 3.5 24.3, week 6.5 13.8, week 9.5 11.7; females, week 3.530 .9 , week $6.515 \cdot 4$, week $9.516 .4 \mu \mathrm{mol} / 1$. $^{*}$ Mean values were significantly different from that for the control group, $P<0.0125$. ANOVA showed significant effects of sex $(P=0.024)$ for total iron-binding capacity and of sex $(P<0.001)$ and vitamin A feeding $(P=0.002)$ for plasma iron.

\section{Iron status of pups}

Haemoglobin levels were increased in the groups given 0 and $75 \mathrm{RE} / \mathrm{kg}$ dietary vitamin A at week 6.5 in the male pups and at week 9.5 in the female pups fed on the diet without added vitamin A (Fig. 3). Differences were relative to the control groups. ANOVA also showed that haemoglobin levels differed between sexes $(P=0.021)$.

Total Fe-binding capacity was increased at week 6.5 in the male pups given $450 \mathrm{RE} / \mathrm{kg}$ feed when compared with the control group. This effect disappeared at week 9.5, when total Fe-binding capacity was reduced below control levels in both male and female offspring that received no vitamin A (Fig. 4). Plasma Fe levels were also below control levels in the female pups given no vitamin A at week 6.5, but this reduction failed to reach significance at week 9.5 (Fig. 4). ANOVA revealed a significant effect of sex on total Fe-binding capacity $(P=0.024)$ and plasma $\mathrm{Fe}(P<0.001)$.

Hepatic Fe concentrations were reduced below control levels in the female pups at week 3.5 in the group given $450 \mathrm{RE} / \mathrm{kg}$ feed and at week 9.5 in the groups given 150 and $0 \mathrm{RE} / \mathrm{kg}$ feed (Fig. 5). Splenic Fe was increased above control levels at week 6.5 in both male and female pups given 75 and $0 \mathrm{RE} / \mathrm{kg}$ feed. At week 9.5 this increase was significant in the male 

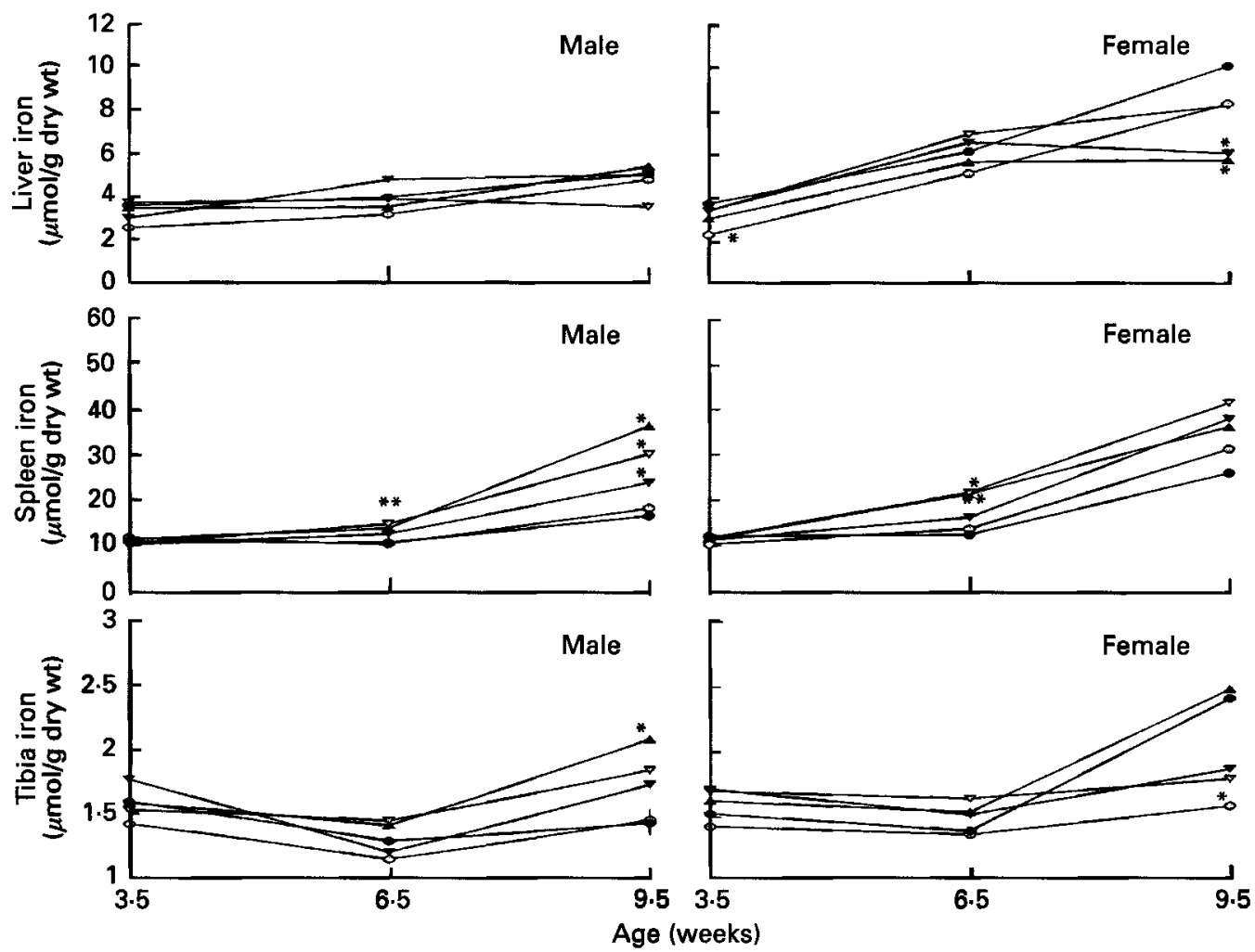

Fig. 5. Iron concentrations in liver, spleen and tibia of male and female rat pups fed on diets containing the following amounts of vitamin A: (O), 1200 retinol equivalents (RE; control group); (O) $450 \mathrm{RE}$; ( $)$ ), $150 \mathrm{RE}$; $(\nabla), 75 \mathrm{RE}$ and $(\mathbf{\Lambda}) 0 \mathrm{RE} / \mathrm{kg}$ feed. Values are means for five animals/group; pooled sE for liver iron were: males, week 3.50 .46 , week 6.51 .34 , week 9.52 .38 ; females, week 3.51 .49 , week 6.52 .32 , week $9.54 .60 \mu$ mol/g; those for spleen iron were: males, week 3.52 .24 , week 6.53 .24 , week 9.56 .24 ; females, week 3.54 .54 , week 6.56 .92 , week $9.519 .99 \mu \mathrm{mol} / \mathrm{g}$; and those for tibia iron were: males, week 3.5 0.92, week 6.5 0.25, week 9.5 0.80; females, week 3.51 .16 , week 6.50 .43 , week $9.51 .04 \mu \mathrm{mol} / \mathrm{g}$. * Mean values were significantly different from that for the control group, $P<0.0125$. ANOVA showed significant effects of sex $(P<0.001)$ and vitamin A feeding $(P=0.018)$ for liver iron, of sex $(P=0.001)$, vitamin $\mathrm{A}$ feeding $(P<0.001)$ and their interaction $(P=0.020)$ for spleen iron, and of sex $(P=0.001)$ and vitamin A feeding $(P<0.001)$ for tibia iron.

rats given 0,75 or $150 \mathrm{RE} / \mathrm{kg}$ diet, in the female pups there were no significant differences due to large variation (Fig. 5). Tibia Fe was also increased above control level in the male but not in the female offspring fed on diets without vitamin $\mathbf{A}$ (Fig. 5). Fe in liver $(P<0.001)$, spleen and tibia $(P=0.001)$ differed between sexes according to the variance analysis.

\section{DISCUSSION}

With the two-generation rat model described here we aimed at inducing chronic vitamin A deficiency with different degrees of severity so as to study the interrelationship between vitamin A and Fe metabolism. Thus we attempted to influence vitamin A status of rat pups as early as at the time of conception by feeding diets with different vitamin A concentrations to the dams. Vitamin A status of the pups was not only influenced through the dams but also directly by consumption of the experimental diets. As from the age of about $12 \mathrm{~d}$ rat pups start to consume solid food in addition to the mother's milk. The first assessment of vitamin A status in the pups was at age 3.5 weeks. Vitamin A status of the 
dams was affected mildly by the amount of vitamin $A$ in the diet. There was no effect on plasma retinol although liver retinol concentrations were reduced significantly (Table 3 ). Liver retinol concentration determines the amount of vitamin A transferred into the milk during the lactation period while plasma retinol levels remain constant (Davila et al. 1985). Thus, the maternal vitamin A status contributed to at least part of the differences in vitamin A status of the pups as measured at the age of $3 \cdot 5$ weeks.

There was no effect of the dietary treatment on maternal plasma retinol levels. This could explain why there was no difference in reproduction outcome among the groups. Wallingford \& Underwood (1987) concluded from their studies in Sprague-Dawley rats that dams require at least $0.011 \mu \mathrm{mol} \mathrm{retinol} / \mathrm{g}$ liver to maintain systemic vitamin A metabolism during pregnancy. In the present study liver retinol concentrations of the dams exceeded these levels substantially. This was almost certainly caused by the fact that the dams were fed on a commercial diet until the age of 10 weeks, when they entered the study. The vitamin A concentration of the commercial diet used was almost five times higher than the recommended level and must have induced high vitamin A stores. The abundant vitamin A of the dams probably caused the initial plasma retinol concentrations of the pups to be higher than those seen by Gardner \& Ross (1993) in a similar experiment.

In the present study, male and female rats differed in plasma retinol levels. From the age of 6.5 weeks, male pups had higher plasma retinol levels than females when given 450 and $1200 \mathrm{RE} / \mathrm{kg}$ feed. Females seem to accumulate more vitamin A in liver. This might partly be explained by lower feed intake and growth rate and thus lower body weight and liver weight in the female pups. Also, the effects of restricted dietary vitamin A on body weight and liver weight were more pronounced in male than in female pups.

Vitamin A deficiency has been shown to affect Fe status in humans (Bloem et al. 1990; Suharno et al. 1993) and rats (Mejía et al. 1979a, b; Sijtsma et al. 1993; Roodenburg et al. 1994, 1996). In the present study the increase in haemoglobin levels and reduction of plasma $\mathrm{Fe}$ in vitamin A deficiency were very small and subject to large variation. Despite this, we found a significant reduction in total Fe-binding capacity and a significant increase in splenic $\mathrm{Fe}$ with vitamin A deficiency in both female and male rats. The increased haemoglobin levels with vitamin A deficiency had been found previously (Koessler $e$ t al. 1926; McLaren et al. 1965; Mejía et al. 1979a; Roodenburg et al. 1994, 1996). This had been associated with haemoconcentration due to water imbalance and reduced growth (Mahant \& Eaton, 1976; Hodges et al. 1978).

Despite the well-known haemoconcentration in rats with vitamin A deficiency, we observed a decrease in total Fe-binding capacity, which had been reported earlier in both humans (Mejía \& Arroyave, 1982; Bloem et al. 1989, 1990; Suharno et al. 1992) and rats with vitamin A deficiency (Mejía et al. 1979a, b; Roodenburg et al. 1994, 1996). It has been suggested that vitamin A deficiency interferes with the synthesis of the glycoprotein transferrin, resulting in low total Fe-binding capacity (Chan \& Wolf, 1987). This in turn might lead to impaired Fe transport, explaining the slightly lowered plasma Fe levels in the rats raised and fed on the diet without vitamin A. Impaired Fe transport might lead to $\mathrm{Fe}$ accumulation in organs. Indeed, we found an increase in splenic Fe concentrations with vitamin A deficiency which has also been reported by Mejía et al. (1979a) and Roodenburg et al. $(1994,1996)$. The extra splenic Fe might be located in the macrophages.

In conclusion, this two-generation experiment resulted in a range of vitamin A-deficient states in young growing rats, and revealed a difference between male and female rats concerning plasma retinol concentrations and the effects of vitamin A deficiency on growth, liver weight and $\mathrm{Fe}$ status. We did find effects of vitamin A deficiency on total Fe-binding capacity and splenic Fe. However, effects of vitamin A deficiency on other Fe variables were unclear in this study. The large variation in variables such as Fe concentrations in the 
different organs, total Fe-binding capacity and plasma Fe concentration might have confounded possible effects of vitamin A deficiency. We must state that the animal model described here is less suitable for studying effects of vitamin A deficiency on Fe metabolism than rat models we have used before. The 10 weeks feeding of male weanling rats with a diet without vitamin A produced a progressive derailment of $\mathrm{Fe}$ metabolism, including increases in splenic Fe and decreases in total Fe-binding capacity (Roodenburg et al. 1994). In young male rats with different degrees of vitamin A deficiency that were produced exactly as described in this paper, we could clearly demonstrate that impaired vitamin A status reduces the efficacy of Fe repletion after the induction of iron deficiency (Roodenburg et al. 1996).

This research was funded by the Dutch Ministry of Education and Science through the Human Nutrition Biology Graduate Training Network. The authors thank Mr Gerrit van Tintelen and Mr Frank van den Broek for their technical assistance.

\section{REFERENCES}

Beaton, G. H., Martorell, R., Aronson, K. J., Edmonston, B., McCabe, G., Ross, A. C. \& Harvey, B. (1993). Effectiveness of Vitamin A Supplementation in the Control of Young Child Morbidity and Mortality in Developing Countries. State-of-the-Art Series, Nutrition Policy Discussion Paper No. 13. Geneva: ACC/SCN.

Bloem, M. W., Wedel, M., Egger, R. J., Speek, A. J., Schrijver, J., Saowakontha, S. \& Schreurs, W. H. P. (1989). Iron metabolism and vitamin A deficiency in children in Northeast Thailand. American Journal of Clinical Nutrition 50, 332-338.

Bloem, M. W., Wedel, M., van Agtmaal, E., Speek, A. J., Saowakontha, S. \& Schreurs, W. H. P. (1990). Vitamin A intervention: short-term effects of a single, oral massive dose on iron metabolism. American Journal of Clinical Nutrition 51, 76-79.

Chan, V. T. \& Wolf, G. (1987). The role of vitamin A in the glycosylation reactions of glycoprotein synthesis in an 'in vitro' system. Biochemical Journal 247, 53-62.

Davila, M. E., Norris, L., Cleary, M. P. \& Ross, A. C. (1985). Vitamin A during lactation: relationship of maternal diet to milk vitamin A content and to the vitamin A status of lactating rats and their pups. Journal of Nutrition 115, 1033-1041.

Gardner, E. M. \& Ross, A. C. (1993). Dietary vitamin A restriction produces marginal vitamin A status in young rats. Journal of Nutrition 123, 1435-1443.

Hodges, R. E., Sauberlich, H. E., Canham, J. E., Wallace, D. L., Rucker, R. B., Mejía, L. A. \& Mohanram, M. (1978). Hematopoietic studies in vitamin A deficiency. American Journal of Clinical Nutrition 31, 876-885.

Koessler, K. K., Maurer, S. \& Loughlin, R. (1926). The relation of anaemia, primary and secondary, to vitamin A deficiency. Journal of the American Medical Association 87, 476-482.

McLaren, D. S., Tchalian, M. \& Ajans, Z. A. (1965). Biochemical and hematologic changes in the vitamin A deficient rat. American Journal of Clinical Nutrition 17, 131-138.

Mahant, L. \& Eaton, H. D. (1976). Effect of chronic hypovitaminosis A on water metabolism in the weanling rat. Journal of Nutrition 106, 1817-1826.

Mejía, L. A. \& Arroyave, G. (1982). The effect of vitamin A fortification of sugar on iron metabolism in preschool children in Guatemala. American Journal of Clinical Nutrition 36, 87-93.

Mejia, L. A. \& Chew, F. (1988). Hematological effect of supplementing anemic children with vitamin A alone and in combination with iron. American Journal of Clinical Nutrition 48, 595-600.

Mejía, L. A., Hodges, R. E. \& Rucker, R. B. (1979a). Clinical signs of anaemia in vitamin A-deficient rats. American Journal of Clinical Nutrition 32, 1439-1444.

Mejia, L. A., Hodges, R. E. \& Rucker, R. B. (1979 b). Role of vitamin A in the absorption, retention and distribution of iron in the rat. Journal of Nutrition 109, 129-137.

Mohanram, M., Kulkarni, K. A. \& Reddy, V. (1977). Hematological studies in vitamin A deficient children. International Journal of Vitamin and Nutrition Research 47, 389-393.

Muhilal, Permeisih, D., Idjradinata, Y. R., Muherdiyantiningsih \& Karyadi, D. (1988). Vitamin A-fortified monosodium glutamate and health, growth, and survival of children: a controlled field trial. American Journal of Clinical Nutrition 48, 1271-1276.

National Research Council (1978). Nutrient Requirements of Laboratory Animals. Washington: National Academy of Science.

Roodenburg, A. J. C., West, C. E., Hovenier, R. \& Beynen, A. C. (1996). Supplemental vitamin A enhances the recovery from iron deficiency in rats with chronic vitamin A deficiency. British Journal of Nutrition (In the Press). 
Roodenburg, A. J. C., West, C. E., Yu, S. \& Beynen, A. C. (1994). Comparison between time-dependent changes in iron metabolism of rats as induced by marginal deficiency of either vitamin A or iron. British Journal of Nutrition 71, 687-699.

Sijtsma, K. W., Van den Berg, G. J., Lemmens, A. G., West, C. E. \& Beynen, A. C. (1993). Iron status in rats fed on diets containing marginal amounts of vitamin A. British Journal of Nutrition 70, 777-785.

Suharno, D., West, C. E., Muhilal, Logman, M. H. G. M., de Waart, F. G., Karyadi, D. \& Hautvast, J. G. A. J. (1992). Cross-sectional study on the iron and vitamin A status of pregnant women in West Java, Indonesia. American Journal of Clinical Nutrition 56, 988-993.

Suharno, D., West, C. E., Muhilal, Karyadi, D. \& Hautvast, J. G. A. J. (1993). Not only supplementation with iron but also with vitamin $A$ is necessary to combat nutritional anaemia in pregnant women in West Java, Indonesia. Lancet 342, 1325-1328.

Wallingford, J. C. \& Underwood, B. A. (1987). Vitamin A status needed to maintain vitamin A concentrations in nonhepatic tissues of the pregnant rat. Journal of Nutrition 117, 1410-1415.

West, C. E., Sijtsma, S. R., Peters, H. P. F., Rombout, J. H. W. M. \& Van der Zijpp, A. J. (1992). Production of chickens with marginal vitamin A deficiency. British Journal of Nutrition 68, 283-291. 